\title{
The Influence of Law of Freeze -thaw Cycles for the Strength Parameter
}

\section{of Intact Loess}

\author{
Kangfeng Yuan ${ }^{a}$ \\ (a, Key Lab of Highway Construction \& Maintenance Technology in Loess Region, Ministry of \\ Transport, PRC, b, Shanxi Key Laboratory of Highway Construction \& Maintenance Technology \\ in Loess Region,Shanxi Transportation Research Institute, Shanxi, Taiyuan 030006, China) \\ ayuankangfeng@163.com
}

Key words: freeze-thaw; Intact loess; strength parameter; triaxial shear test; stress characters Abstract: At present, the research is not enough for the correlation of loess strength parameter and freeze-thaw cycles in domestic. The paper aims how the change of freeze-thaw cycles influence the stress characters of intact loess by consolidated drained triaxial shear test for the Shanxi loess.The results showed that: the strength parameter of intact loess decreases with the increasing of freeze-thaw cycle. The reduce of strength parameter $\mathrm{c}$ is obvious with the increasing freeze-thaw cycles. The reduce of strength parameter $\varphi$ is not obvious with the increasing freeze-thaw cycles.

\section{Introduction}

The main reason for the change of soil mechanical properties by freezing and thawing is the change of soil structure, which is the connection force between soil particles and the rearrangement of soil particles. The influence of freeze-thaw on the engineering properties of soil can be roughly analyzed from two aspects: the soil water properties, the physical properties and the soil mechanical properties. Jiang Zong-bin et $\mathrm{al}^{[1]}$ think that under the same times of freezing-thawing cycles, shear strength increases with increasing of confining pressure. Under the sameconfining pressure, internal frictional angle, cohesive strengthand shear strength present the tendency of reducing first and thenincreasing with the increase of the times of freezing-thawing cycles, however moisture content presents the tendency of increasing first then reducing with the increase of the times of freezing-thawing cycles. The turning point is about in the position of 7 times. Wang Jing et $\mathrm{al}^{[2]}$ think that the elastic modulus increases with confining pressure increase for the same kind of soil under the same freeze-thaw cycles.Elastic modulus with the same confining pressure decreases with the of freeze-thaw cycles; Under the same confining pressure and the same freeze-thaw cycles, elastic modulus increases with the plasticity index. The exponential function is adopted for multiplenonlinear fitting. The relationship between elastic modulus and confining pressure, plasticity index, freeze-thaw cycles is obtained and shows a good correlation. Bi Gui-quan et $\mathrm{al}^{[3]}$ think that At the end of freeze-thaw cycle, there was a small settlement in samples, which resulted probably from soil particle rearrangement caused by strong freezing and thawing action. In addition, freezing and thawing actions decreased gradually the dry density of loess samples. The dry density in upper part was larger than that in bottom part.The studies showed that: the freezing thawing cycles can lead to the engineering properties of 
the soil great changes, which lead to deformation and even instability of engineering facilities in cold areas. However, for the law of strength parameter and freeze-thaw, there is rare research on the intact loess ${ }^{[4]-[11]}$.

The conventional static triaxial tests are the commonly methods to study the strength characteristics.With the help of consolidated drained triaxial tests to research the characteristics of intact loess for different freeze-thaw cycle. The research have certain theoretical significance for the study of loess freeze-thaw characteristics. At the same time, it provides reference for the future research of loess structural and strength.

\section{The loess of test}

The loess of tests is taken from certain foundation at the Jinnan district, in a depth of $4 \mathrm{~m}$ below the surface, which is brownish yellow, silty clay, soil evenly, with a small amount of worm holes. The soil samples have been whittled to length $30 \mathrm{~cm} \sim 45 \mathrm{~cm}$ cube in the field,with the plastic wrapped well and indicated the vertical direction, transported back to the laboratory. The natural moisture content of soil samples was $9.8 \%$.

\section{Test Instruments and Test Method}

\section{Test Instruments}

The test instrument is the conventional triaxial shear apparatu. The pressure will directly load to the roof through counterproductive of fixed beam gantry, The steel ring and pressure sensor will measure pressure.

The test instrument of freeze-thaw is the constant temperature and humidity box which is produced by a instrument factory of nanjing. The temperature control precision is higher.

\section{Test Method}

Prepare four group intact triaxial specimen (diameter $3.91 \mathrm{~cm}$, height $8 \mathrm{~cm}$ ). Adjust the freezing temperature (minus twenty degrees), record the time, after 12 hours, adjust the temperature (thaw temperature is 5 degrees), start the thawing stage, after 12 hours, take out the soil sample and carry out the three axis test. The number of freeze-thaw cycles was 1 times, 2 times, 4 times and 8 times.Configure pressure was separate $100 \mathrm{kPa}, 200 \mathrm{kPa}, 400 \mathrm{kPa}$ for consolidated drained shear test of Each group sample(the number is four); specimen installed before applying confining pressure, open the drain valve to consolidation, start motor to cut after the end of consolidation. The final shutdown standard is to see the soil samples which have obvious cracks or dislocation or axial deformation reaches $12 \mathrm{~mm}$.

\section{Test Results and Analysis}

The influence of cycle times on strength characteristics of intact loess

According to formula 1:

$$
\tau=c+\sigma \tan \phi
$$

The law of intact loess shear strength changing with freeze-thaw cycles is indicated in figures 1 to 4 : 

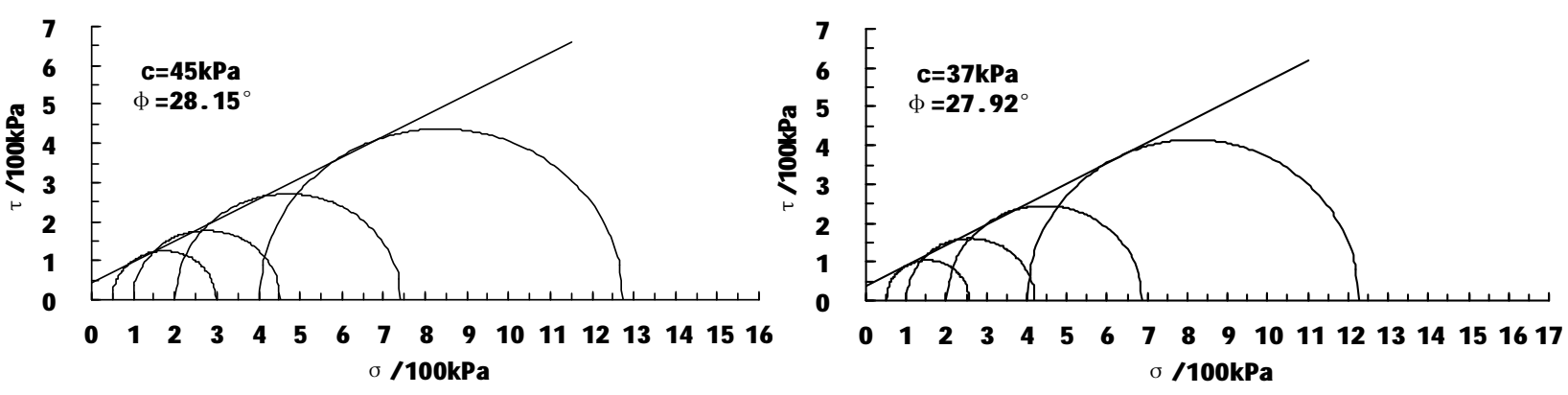

Figure 1. Shear strength lines for cycle times 1

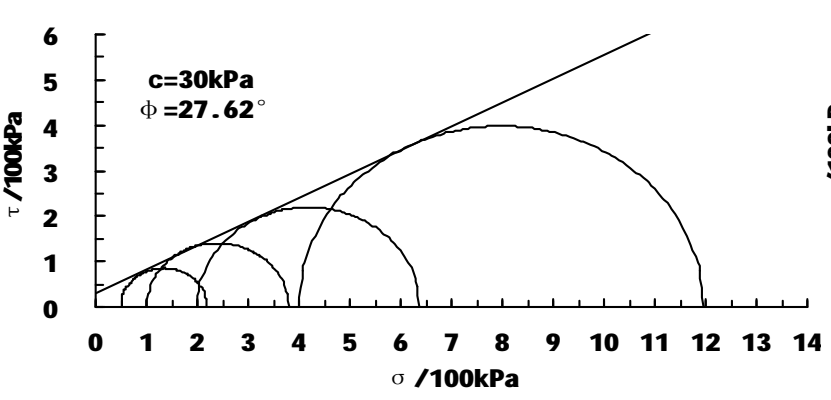

Figure 2. Shear strength lines for cycle times 2

Figure 3. Shear strength lines for cycle times 4 Figure 4. Shear strength lines for cycle times 8

Figure 1-4 show that the strength parameter of intact loess decreases with the increasing of freeze-thaw cycles.

\section{The law of strength parameter changing with freeze-thaw cycles for intact loess}

The law of intact loess strength parameter under different freeze-thaw cycles is indicated in figures 5:

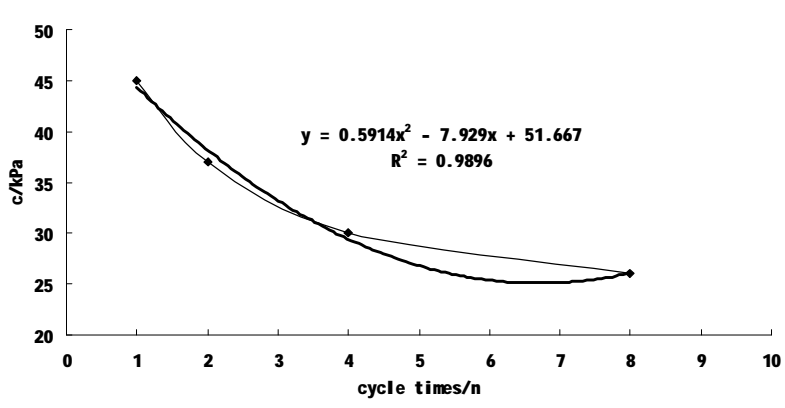

(a) Parameter c

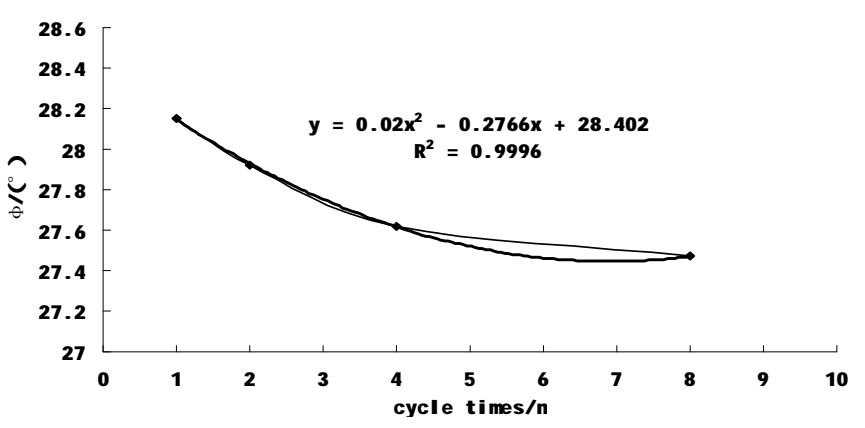

(b) Parameter $\varphi$

Figure 5. Relationship between strength parameter and freeze-thaw cycle times

Figure 5 show that with the increase of freeze-thaw cycles, the strength reduce. The reduce of strength parameter $\mathrm{c}$ is obvious with the increasing freeze-thaw cycles. The reduce of strength parameter $\varphi$ is not obvious with the increasing freeze-thaw cycles.

According to Figure 5,the relationship of strength parameter and freeze-thaw cycles can be converted to the following formula:

$$
\begin{aligned}
& c=0.5914 n^{2}-7.929 n+51.667 \\
& \phi=0.02 n^{2}-0.2766 n+28.402
\end{aligned}
$$

According to formula 2, formula 3, to predict the strength parameter for certain freeze-thaw cycles, have some theoretical significance for the relation research. 


\section{Conclusions}

In this paper, conventional triaxial test apparatus and the constant temperature and humidity box is applied to study the strength parameter of intact loess under different freeze-thaw cycles. The main conclusions are as follows:

(1) the strength parameter of intact loess decreases with the increasing of freeze-thaw cycles.

(2) The reduce of strength parameter $\mathrm{c}$ is obvious with the increasing freeze-thaw cycles. The reduce of strength parameter $\varphi$ is not obvious with the increasing freeze-thaw cycles.

\section{Acknowledgements}

The paper is Sponsored by the Research Project of Shanxi Youth Science and Technology Research Fund [201701D221212].

\section{References}

[1] JIANG Zong-bin, JIANG An-nan. Experimental study on soft soil subgrade under freeze-thaw cycles by triaxial tests in Dalian area [J]. Journal of Dalian Maritime University, 2013, 39(3):117-120.

[2] WANG Jing,LIU Han-bing, WU Chun-li. Influence of freeze-thaw cycles on elastic modulus of subgrade soil with different plasticity indices [J]. Rock and Soil Mechanics, 2012,33 (3665-3668).

[3] BI Gui-quan, ZHANG Xia, LI Guo-yu et,al. Experiment of impact of freezing-thawing cycle on physico-mechanical properties of loess [J]. Journal of Lanzhou University of Technology, 2010,36(2):114-117.

[4] SONG Fei. The study on the stability and deformation mechanism of huazicun loess landslide [J].SHANXI SCIENCE \& TECHNOLOGY of COMMUNICATIONS, 2012,216(3):13-15.

[5] LI Xu-hua.The Rational Slope Type Research on Loess High Slope [J].SHANXI SCIENCE \& TECHNOLOGY of COMMUNICATIONS, 2012,214(1):29-30.

[6] LIAO Xiong-hua, WANG Lei-xiao, ZHANG Ke-xu et,al. An inelasto-plastic constitutive model for soil[J]. Rock and Soil Mechanics, 2002(1):41-45.

[7] Konrad J M. Hydraulic conductivity of kaolinite-silt mixtures subjected to closed-system freezing and thaw consolidation[J].Canadian Geotechnical Journal, 2000, 37(4):857-869.

[8] WANG Yong-zhong, LIU Xiong-jun, AI Chuan-jing et,al. Experimental investigation on shear strength parameters candpfor a temporarily frozen soil in South China [J]. Engineering Journal of Wuhan University, 2010,43(2):198-202.

[9] SHENG Wei-gao,LI Guo-wei,YUAN Jun-ping. Stability analysis of high slopes based on the influence of water content change on soil strength [J]. Advances in Science and Technology of Water Resources, 2009, 29(1):12-15.

[10] Yang Chengsong,He Ping,Cheng Guodong,et al. Testing study on influence of freezing and thawing on dry density and water contentof soil[J]. Chinese Journal of Rock Mechanics and Engineering,2003,22(Supp. 2):2695-2699.

[11] Jennnigs J E.A revised effective stress law for use in the prediction of behavior about unsaturated soils[A].Poreeeding of Pore Pressure and Suction in soils[C],London, U.K.,1961,26-30. 